\title{
Physical Activity Intervention for Loneliness (PAIL) in community-dwelling older adults: a randomised feasibility study
}

\author{
Anastasia V. Shvedko ${ }^{1 *}$, Janice L. Thompson', Carolyn A. Greig ${ }^{1,2,4}$ and Anna C. Whittaker ${ }^{1,3^{*}}$
}

\begin{abstract}
Background: Low quality social relationships in older adults are strongly associated with feelings of loneliness. Physical activity interventions could reduce loneliness and improve psychological well-being, among other health benefits. The aim of this study was to examine the feasibility of a Physical Activity Intervention for Loneliness (PAIL) in community-dwelling older adults at risk of loneliness.
\end{abstract}

Methods: The PAlL feasibility study was a 12-week randomized controlled feasibility trial (RCT) conducted in Birmingham, United Kingdom, from February 2018 to August 2018, and ran in two waves of data collection. Eligible participants were community-dwelling adults aged 60 years and older, sedentary (less than 20 min of moderate-tovigorous PA (MVPA) a week), and at risk of loneliness. The intervention included once-weekly group walk and health education workshop up to 90 min per session in total, with a wait-listed (WL) control group. The primary feasibility outcomes were to estimate recruitment, retention rates and adherence to the intervention. Secondary outcome measures (not blinded assessment) were body mass index, blood pressure, physical activity and psychosocial variables. Process and outcome evaluations were conducted using focus groups interviews. The recruitment and retention progression criteria for the definitive large-scale RCT was set a-priori.

Results: Forty-eight participants were recruited over 4 months with a recruitment rate of 25\% (48/195); 52\% (25/48) met the inclusion criteria and 100\% (25/25) were randomised into the intervention $(n=12)$ and WL control groups $(n=13)$. Participants were 25 older adults (mean (SD) 68.5(8.05) years), 14 (56\%) female, and 18 (72\%) white. At 12 weeks, 10/12 (83.3\%) intervention and 10/13 (76.9\%) control participants completed the final assessments. The average attendance rate was 58.3\% for the intervention group (range 33.0\%-75.0\%) and 42.3\% (range 23.1\%-69.2\%) among controls. The a priori recruitment and retention criteria for progression were not met. No serious adverse events occurred. The focus group results identified three themes which showed overall positive experiences of participation in PAlL in terms of (1) study design and intervention; (2) walking sessions; and (3) health education workshops.

Conclusions: The findings suggest that community-dwelling older adults at risk of loneliness found the intervention and measures acceptable and could safely participate. However, a more extensive and robust strategy would be needed to support adequate recruitment of lonely older adults and adherence into a definitive RCT.

Trial registration: Clinicaltrials.gov, NCT03458793

Keywords: Feasibility study, Physical activity, Loneliness, Older adults, Randomised controlled trial

\footnotetext{
*Correspondence: axs1235@bham.ac.uk

'School of Sport, Exercise and Rehabilitation Sciences, University of Birmingham, Birmingham, UK

Full list of author information is available at the end of the article
}

(c) The Author(s). 2020 Open Access This article is licensed under a Creative Commons Attribution 4.0 International License, which permits use, sharing, adaptation, distribution and reproduction in any medium or format, as long as you give appropriate credit to the original author(s) and the source, provide a link to the Creative Commons licence, and indicate if changes were made. The images or other third party material in this article are included in the article's Creative Commons licence, unless indicated otherwise in a credit line to the material. If material is not included in the article's Creative Commons licence and your intended use is not permitted by statutory regulation or exceeds the permitted use, you will need to obtain permission directly from the copyright holder. To view a copy of this licence, visit http://creativecommons.org/licenses/by/4.0/. The Creative Commons Public Domain Dedication waiver (http://creativecommons.org/publicdomain/zero/1.0/) applies to the data made available in this article, unless otherwise stated in a credit line to the data. 


\section{Background}

Maintenance of social connectedness throughout the lifespan is an important aspect of successful ageing [1]. The disruption of established social patterns or poor quality of social relationships is strongly associated with loneliness especially in older adults [2]. Defined as a discrepancy between a person's desired and actual social relationships [3], loneliness and a lack of social relations are considered to be high risk factors for morbidity and mortality, and the negative impact of loneliness can be as harmful as smoking fifteen cigarettes a day [4]. Due to the deteriorating health condition of older adults and less ability to engage in social connections, the early prevention of loneliness in community programmes seems prudent.

Due to deteriorating health associated with ageing, older adults are highly predisposed to declines in cognitive and physical function [5]. However, regular exercise in older adults at the recommended minimum of 150 min of moderate PA per week performed in any length of bouts [6] can contribute to the maintenance of physical health. Additional benefits are associated with muscle strengthening and balance exercises performed in $10 \mathrm{~min}$ bouts for falls prevention [7]. Moreover, active older adults retain cognitive function at a high level throughout their older years, which is a very important aspect of social life and well-being [8, 9]. It is a health behaviour that can increase peripheral social networking and the acquisition of new social contacts due to engagement in a variety of physical and leisure activities by older adults outside the home. In turn, this can replace or compensate for lost social connections for older adults with feelings of loneliness, and turn these feelings into meaningful social connections based on the social compensation model [10]. PA improves psychological and emotional well-being leading to direct health benefits based on the so-called feel-good effect of exercise identified in the literature [11], which is associated with increases in serotonin, monoamine and neurotrophin production and reductions in the stress hormone cortisol [12].

Mechanisms of action of PA interventions are suggested to relate to loneliness reduction models, stress reduction and increased social support during activities. The social compensation model [13] suggests that PA can work via compensation for lost meaningful social connections due to increased peripheral social networking during friendly conversations between participants [14]. The broaden-and-build theory of positive emotions [15] posits that enjoyable forms of PA generate happiness and bring positive emotions, which in turn could be associated with loneliness reduction [16]. Based on the stress/social support model [17], social networks promote well-being that is associated with loneliness reduction in older adults. Finally, the tripartite model of group identification has been shown to be effective in group-based PA settings among specific population groups, such as lonely seniors, due to a sense of social identification $[18,19]$. This model considers three aspects, such as cognitive (social categorisation, i.e. the degree by which an individual categorises him/herself as similar to other group members), affective (i.e. the degree to which an individual feels affectively attracted to the other group members), and behavioural (interdependence, i.e. the degree to which an individual evaluates his/her group as important for teaching objectives) $[18,19]$. Through shared interests and goals during engagement in physical activities social activity is boosted and leads to group identification through the feeling of social attraction to other group members.

A previous review found that few PA interventions for loneliness reduction have been conducted in community settings [20]. This is also consistent with previous systematic reviews and meta-analyses [2, 18, 21, 22]. Results of metaanalysis performed for social functioning (as a sub-domain of health-related quality of life) in this review showed, that specific aspects of PA interventions can successfully influence social health [20] with the strongest effects being obtained for group setting exercise interventions, with delivery by a health/medical professional, and in a diseased rather than healthy population [20]. In addition, the majority of studies used a cross-sectional or longitudinal design, which does not allow determination of causality and limits the rigour of the research evidence [18]. Others assess loneliness as a secondary outcome within a number of other psychosocial outcomes, which limits the ability to fully examine the effectiveness of these interventions for reducing loneliness [23].

Further, a number of moderating, such as global $[23,24]$ and domain-specific self-efficacy [25] and mediating (driving the influence of PA on loneliness) factors, such as social support [26] between loneliness and PA may help to determine additional pathways of any PA intervention effects.

Bearing in mind the limitations of the current literature, understanding the mechanisms through which PA may reduce loneliness may bring new insights to the design of novel and effective PA interventions [18]. Further research is needed to explore the association between loneliness, self-efficacy and social support in the context of PA interventions for older adults. However, before the mechanisms can be fully understood, the practicalities and feasibility of implementation of such interventions with older adults should be tested in a feasibility trial [27] before proceeding to a definitive RCT. In order to assess participant experiences of such interventions, the present study utilised a mixed-methods research design, defined as the class of research where the 
researcher mixes or combines quantitative and qualitative research techniques, methods, approaches, concepts or language into a single study [28]. This research design can add valuable knowledge into a feasibility study. The aim of the study was to examine the feasibility of the Physical Activity Intervention for Loneliness (PAIL) intervention in community-dwelling older adults at risk for loneliness. For the planned future large-scale RCT, the primary hypothesis was that, compared with the inactive control group, participants in the intervention group would report a greater decrease in loneliness. The secondary hypothesis was that participants in the intervention group would significantly increase their amount of physical activity engagement per week, and this would be associated with greater positive changes in other psychosocial and health outcomes compared with the control group participants. The following specific aims of this feasibility study were to estimate:

1. Recruitment rate, attendance and retention rates (number of participants completing the study as a proportion of those randomised).

2. The acceptability of the intervention by participants, and willingness to participate.

3. The appropriateness of the statistical methods of data analysis used.

4. The required sample size for a future large-scale RCT derived from a power calculation.

5. The acceptability of measures, and the most suitable primary outcome measure for a future large-scale RCT.

In addition, to reflect the aims of a future large-scale RCT that this feasibility study was seeking to inform, the effect sizes between the intervention and control groups were examined; however, the analysis was exploratory due to feasibility studies not being adequately powered to test the effectiveness of the intervention [29].

\section{Methods/design}

The full description of methods in available elsewhere [30]. A brief description is presented here. PAIL was a two-arm, 12-week randomised feasibility trial with a waitlisted control group delivered in Birmingham, United Kingdom, from February 2018 to August 2018, and ran in two waves of data collection. The trial was approved by the Science, Technology, Engineering and Mathematics (STEM) Research Ethics Committee of the University of Birmingham, UK (ERN_16-1419A). This feasibility study was guided by a populated CONSORT Extension to Pilot and Feasibility Trials (Additional file 1) and template for intervention description and replication (TIDieR) checklist [31] (Additional file 2). Written informed consent was obtained from all participants prior to entry into the study.

\section{Participants}

\section{Recruitment}

Participants were recruited in two waves from September 2017 to April 2018, from the local neighbourhood (households) and communities in Birmingham via leaflets. Additional recruitment was facilitated during the eligibility screening [32]. Recruitment was aimed to be at a rate of 10 participants a month (to a minimum of 40 participants) for estimation of the critical parameters of the feasibility study [33].

Initial eligibility was phone-based with the further eligibility screening conducted at the university centre. After providing informed consent, participants were invited to a presentation meeting about the study. This was delivered at the university by the main researcher (AS), and included a detailed description of the project aims, methods and procedures, and a Question and Answer session. Attendees were invited for further eligibility screening at the university. Potentially eligible participants identified after baseline screening were randomised into the intervention or a WL control group using a computergenerated random sequence performed by an external researcher not involved in the delivery of the intervention or outcome assessment. Participants were informed about the group allocation by e-mail or a phone call by a person not involved in assessments or delivery of the intervention. At the outcome assessment level, participants who were assessors of their own psychosocial outcomes using questionnaires, were blinded to their group allocation at the time of completing the initial questionnaires. Intervention providers who were responsible for outcome assessments were not blinded to the intervention delivery as this would not be possible, given that the $\mathrm{PhD}$ student researcher (AS) conducted the study and walks.

\section{Eligibility}

Participants were eligible if they were (1) communitydwelling older adults aged 60 years and older; (2) previously sedentary (i.e. less than $20 \mathrm{~min}$ of moderate-tovigorous PA (MVPA) per week over the past month) [34]; (3) at risk of loneliness and having $\geq 6$ out of 9 points on the 3-item loneliness scale during the phone screening [35]; (4) physically mobile as measured using the short physical performance battery (SPPB) [36] with a score $\geq 9$ out of 12 [37]; (5) having chronic diseases but ambulatory; (6) able to give written informed consent; and (7) English speaking and able to complete paper and pencil questionnaires. Exclusion criteria were as follows: $<60$ years old, regularly physically active or already engaged in another PA intervention, socially active, having a disease that seriously precluded participation in PA, having a cognitive impairment as assessed by the Montreal Cognitive Assessment (MOCA) [38] with a score $\geq 22$ out of 30 [39] and not English literate. 


\section{Intervention development and delivery}

The development of the PAIL intervention was a result of collaborative work of the research group based on the characteristics of effective interventions obtained from our previously published systematic review [20]. The theory of active engagement [40] influenced the choice of moderators such as social support and self-esteem through an acquired sense of purpose and confidence during enjoyable forms of PA. The walking group leader attended a training course focused on exercise for older adults "Move it or lose it" [41] and was a certified group exercise instructor. The intervention was a group walking intervention with an education workshop on healthy ageing topics alongside each walking session once per week. After the pilot of the entire intervention with five people and feedback obtained at focus group interview conducted in March 2018, minor changes were needed to modify the delivery approach of the intervention. Firstly, it was suggested to facilitate the recruitment of participants by contacting the Birmingham 1000 elders group [42] and the BVSC consortium [43] to advertise the intervention for the summer period. Due to a small number of participants per group, the intervention was lacking the necessary social interactions between participants. Therefore, it was suggested to add new participants who were eligible to join the current groups, and identify the start date of their 12-week intervention from the day they joined (i.e. on a rolling basis). Participants received a weekly e-mail with information about the walking route and a topic of the workshops to set appropriate expectations and help them prepare for the discussion. Weekly information about social events was added to support local engagement with activities and facilitate within group social support. Additionally, free access was gained to Winterbourne House and Gardens (https://www.winterbourne.org.uk/) to deliver a healthy workshop, which included free beverages.

\section{Interventions}

The PAIL feasibility study was a 12-week intervention consisting of group walks and health educational/social interaction workshops performed once weekly for a duration of up to $90 \mathrm{~min}$ per session. The design and features of the PAIL intervention were derived from the findings from a systematic review of PA interventions for loneliness by Shvedko et al. [20]. The theory of active engagement [40] influenced the choice of moderators such as social support and self-esteem through an acquired sense of purpose and confidence during enjoyable forms of PA. The PAIL was a face-to-face intervention delivered in small groups (up to 89 people per group) by a trained walk leader certified in group exercise for older adults and run in various locations and parks in Birmingham, UK. Prior to the first walking session, participants received a copy of a General
Practitioner (GP) letter to inform their doctor of participation. Walking sessions were based on the principles of gradual progression and adaptation to PA [44]. The intensity of the walks was light-to-moderate and was monitored objectively by heart rate monitors using the age-predicted heart rate maximum $\left(\mathrm{HR}_{\max }\right)$ method [45] and subjectively using the talk test [46] and the 0-10 Borg Ratings of Perceived Exertion scale (RPE) [47]. Participants had to talk back comfortably during exercises using the talk test [46], and rate their RPE from 2 to 4 [47]. Participants followed a trained walking leader via a specific route (Additional file 3). A warm-up preceded each session followed by an end of session cool-down and breathing exercises. Group walking sessions were followed by health education/social interactions workshops on a variety of healthy ageing topics such as eye hygiene, mental health and well-being, preventing falls, social support, nutritional guidelines, and PA recommendations for older adults where participants shared their knowledge and experiences about the topics discussed.

\section{Intervention group}

After randomisation, participants in the intervention group started the 12-week intervention.

\section{Wait-listed control group}

Participants in the WL control (delayed intervention) group started the intervention after their follow-up measures were completed, approximately 12 weeks postrandomisation.

\section{Measures}

All measures were conducted at the host academic institution at baseline and immediately post the intervention period. Participants provided socio-demographic information about their age, gender, ethnicity, marital status, living arrangements, level of education, any children, employment status and any medical conditions. Cognitive function was assessed using a Montreal Cognitive Assessment scale (MOCA) designed to test mild cognitive impairment [38]. Physical functioning was assessed using the short physical performance battery (SPPB) [36]. Height was measured to the nearest $0.1 \mathrm{~cm}$ using a stadiometer (Seca AG, Reinach, Switzerland) and recorded in metres. Weight was assessed using weighing scales (Tanita UK Ltd., Middlesex, UK) to the nearest $0.1 \mathrm{~kg}$. Resting blood pressure (BP rest, $\mathrm{mm} \mathrm{Hg}$ ) was measured using a portable semi-automatic OMRON sphygmomanometer (OMRON HEM705CP sphygmomanometer; Omron Matsusaka Co Ltd, Japan). Physical activity was measured using ActivPAL accelerometers (PAL Technologies Ltd. Glasgow, UK) at baseline and immediately post intervention over a continuous 7-day period of awake and sleeping (24 h a day) except when bathing or swimming [48]. 


\section{Questionnaires}

Loneliness was assessed using the 8-item UCLA Loneliness Scale (UCLA-8) [49]. Social support was assessed using the 20-item Medical Outcomes Study Social Support Survey (MOSSSS) [50]. Social networks were categorised using the 6-item Lubben's Social Network Scale (LSNS-6) [51]. Depression and anxiety were assessed using the 14-item Hospital Anxiety and Depression Scale (HADS) [52]. Self-efficacy for exercise was measured using the revised 9-item Self-Efficacy for Walking/Exercise Scale (SEE), using a paper-and-pencil format [53]. Satisfaction with level of social contacts (SSC) was measured with the question "How satisfied are you with your social contacts?" [54]. Expected outcomes and barriers for exercise were measured using the Expected Outcomes and Barriers for Habitual Exercise scale [55] adapted for the older adult population. Four questions related to sport competence were deleted from the expected outcomes sub-scale due to irrelevance for this population group [55]. The expected outcomes and barriers for exercise scale has demonstrated good internal consistency from 0.66 to 0.85 , and a high testretest reliability of 0.78 in previous research [55].

\section{Qualitative assessments}

To understand participants' experiences of taking part in the PAIL feasibility trial, focus groups were conducted at the mid-point (between week 4 and 5) and at the end of the 12-week intervention using semi-structured discussions in groups of 4-9 people per group of mixed gender (Additional files 4,5 ) on the following topics: reasons for participation, progress on intervention delivery and possible barriers to attending. The research team iteratively analysed the mid-point data to identify if any alterations in the intervention were required based on the participants' feedback. Focus groups were audio recorded using a digital recorder and transcribed verbatim. An independent trained focus group leader acted as moderator and facilitator of the focus groups [56].

\section{Feasibility outcomes}

The following specific aims of this feasibility study were assessed:

1) Attendance was calculated as the total number of attended sessions divided by the total number of sessions of the intervention and recorded as a percentage.

2) Recruitment rate was calculated as the number of individuals responding to advertisements and friends' referrals out of a total number of formal invitations given/advertisements placed (including web-based advertisements, advertisements placed in the local cohort groups and poster and leaflet material disseminated in the community). Recruitment rate was recorded as a percentage, e.g. $25 \%$ (48/195). It is acknowledged that advertisements may have reached a larger number of individuals, but it was impossible to quantify this.

3) Retention rate was calculated as number of participants completing the study as a proportion of those randomised.

4) The assessment rate of questionnaires was evaluated as the total number of completed questionnaires divided by the total number of questionnaires and recorded as a percentage.

5) The suitability of the statistical methods of data analysis was investigated using reliability analyses. Internal consistency reliability (Cronbach's alpha) was calculated at each time point (pre and post) and averaged to give overall reliability. The expected outcomes and barriers for exercise questionnaire were completed twice at baseline, with a week between measures, to allow for testretest reliability analysis.

6) The acceptability of the intervention by participants, and willingness to participate was assessed using focus group. The focus group transcripts were analysed using a phenomenological inductive approach [57], and these data were used to guide the research team in improving the quality of the delivered intervention by informing positive changes in the methodology and design of the intervention for the future implementation in a consequent study.

7) Statistical power and sample size estimation was calculated for meaningful potential future primary outcomes (e.g. loneliness or social support) using a method based on the differences in means between the intervention and control groups, using the Gpower software [58].

8) An effect size (ES) was calculated for loneliness, social support, social networks, anxiety and depression, self-efficacy for exercise, satisfaction with level of social contacts, and the expected outcomes and barriers for exercise. Means (M) and standard deviations (SD) were used to investigate the effect size for change in loneliness using mixed between (intervention group vs. control group) and within (over time) repeated-measures analysis of variance (ANOVAs) with post hoc comparisons.

\section{Data monitoring}

The data monitoring committee for this project was the supervisory research team (three academic supervisors). They were responsible for checking accuracy of quantitative data upon assembly of the final database following completion of data collection prior to data analysis. The 
qualitative data were analysed iteratively by AS with independent analysis and oversight by a member of the supervisory team with expertise in qualitative and mixed methods research (JT). AS was responsible for monitoring and reporting spontaneous adverse events or any unintended trial effects to the supervisory team, and the primary supervisor (AW). The trial was also subject to independent audit request by the sponsor, the University of Birmingham, by a team independent of the supervisory/research team.

\section{Data collection}

Data were collected at the university facility at screening, baseline and post-intervention period (12 weeks after the start of the intervention). After providing baseline eligibility screening, potential participants were offered a total of five visits for health assessments at the university facility. Participants in the intervention group had an additional sixth visit for attending the mid-point focus group.

\section{Sample size}

As this was a feasibility study to inform the design of the future large-scale RCT, a total targeted sample of 40 older adult participants was considered necessary to be recruited for estimation of the critical parameters [33] with 20 in the intervention group and 20 in the WL control group.

\section{Progression criteria}

The progression criteria to a definitive large-scale RCT were the following: (1) no any serious adverse events, such as hospitalisation, life-threatening condition, death and any adverse events associated with the intervention experienced by less than $5 \%$ of participants per group; (2) recruitment rate of no less than $75 \%$ by the end of the four months recruitment period; and (3) retention rate of no less than $75 \%$ in each group at 12 weeks (endpoint). If all three criteria were not met, there would be insufficient evidence to justify proceeding to the definitive RCT. No targets were set for other feasibility outcomes, e.g. questionnaire completion rates or attendance at the intervention sessions.

\section{Data analysis}

Quantitative data were analysed using SPSS version 22.0 for Windows (SPSS Inc., Chicago, IL) employing an intentionto-treat analysis (based on their treatment allocation and irrespective of participants' adherence or withdrawal) [59]. The level of significance was set at $p<.05$; however, any hypothesis testing was preliminary, and any results were interpreted with caution as this feasibility study is underpowered and the analyses based on small numbers. Baseline differences between groups for continuous data (e.g. age, BMI, resting blood pressure, number of comorbidities, cognitive and physical functioning, and outcomes of questionnaires) were analysed using one-way analysis of variance (ANOVA). Chi-squared tests were applied for nominal data (e.g. gender, ethnicity, marital status, living arrangements, level of education, children, and employment status). For descriptive statistics, data were presented as means $(\mathrm{M})$ and standard deviations (SD). Nominal data were presented as number $(\mathrm{N})$ and percentage. Mixed between (group) and within (time) repeated-measures ANOVAs with post hoc comparisons were applied to investigate the effect of the intervention versus control on psychosocial outcomes (loneliness, social support, support networks, depression, anxiety, self-efficacy for exercise, satisfaction with level of social contacts), expected outcomes and barriers for exercise and accelerometer data. The accelerometer data were analysed using the ActivPAL software V7.1.18 (PAL technologies, Scotland, UK). Recorded data were downloaded to a computer, and data for average daily amount of stepping (step counts), average time lying and sitting $(\mathrm{h})$ in increments of $15 \mathrm{~s}$, average time standing $(\mathrm{h})$, and energy expenditure (EE, MET/h) were analysed using mixed between (intervention group) and within (time) ANOVAs. For the Expected Outcomes and Barriers for Habitual Exercise scale [55], additional test-retest reliability was calculated via correlation. In order to explore which outcome measures are likely to be most important for the main trial, Pearson's correlations were performed between calculated change scores over time in the experimental group for all psychosocial outcomes (Lubben's social networks, loneliness and self-efficacy for exercise) and change scores for averaged daily physical activity (time lying/sitting (h), time standing (h), time stepping (h), step counts, sit to stand transitions ( $\mathrm{n}$ ) and energy equivalent (METs/h)). Statistical power and sample size estimation for a future largescale RCT were calculated for meaningful outcomes (e.g. loneliness or social support) using the method based on the differences in means between the intervention and control group using the G-power software Version 3.1 [58].

\section{Qualitative study}

Qualitative data were thematically analysed by two research team members independently using a phenomenological inductive approach [57]. Transcripts were returned to participants for comments/correction to ensure transparency and trustworthiness of the data (member checking) [60]. Validated transcripts were read several times by the two independent researchers to obtain an overall meaning. Then, themes and subthemes with important meanings common across all participants were derived from the obtained data. Results were compared through discussion between reviewers [61]. Data were pseudoanonymised with a unique identification number (ID) and stored confidentially in locked filing cabinets/on password protected university computers accessible only to the 
research team. Audio recordings were destroyed after the recordings were transcribed verbatim.

\section{Results}

\section{Participant characteristics}

Twenty-five participants aged 68.5(8.05) years (mean (SD), range 60-92 years) healthy, inactive, communitydwelling older adults, 14 (56\%) female, and 18 (72\%) white. Baseline descriptive statistics of participants are shown in Table 1.

Table 1 Baseline socio-demographic, anthropometric and healthrelated characteristics of study participants by group $(n=25)$

\begin{tabular}{|c|c|c|}
\hline Variable & $\begin{array}{l}\text { Intervention } \\
(\boldsymbol{n}=12)\end{array}$ & $\begin{array}{l}\text { Control } \\
(\boldsymbol{n}=13)\end{array}$ \\
\hline Age, years & $68.4(5.9)$ & $67.3(11.5)$ \\
\hline Male, $n(\%)$ & $5(41.7)$ & $6(46.2)$ \\
\hline \multicolumn{3}{|l|}{ Ethnicity, n (\%) } \\
\hline White & $7(58.3)$ & $11(84.6)$ \\
\hline Black & $2(16.7)$ & $0(0)$ \\
\hline Asian & $1(8.3)$ & $1(7.7)$ \\
\hline Other & $2(16.7)$ & $1(7.7)$ \\
\hline \multicolumn{3}{|l|}{ Marital status, n (\%) } \\
\hline Married & $4(33.3)$ & $2(15.4)$ \\
\hline Single/never been married & $4(33.3)$ & $4(30.8)$ \\
\hline Divorced/separated & $2(16.7)$ & $5(38.5)$ \\
\hline Widowed & $2(16.7)$ & $2(15.3)$ \\
\hline Living alone, $n$ (\%) & $8(66.7)$ & $9(69.2)$ \\
\hline \multicolumn{3}{|l|}{ Education, $n(\%)$} \\
\hline No qualification & $2(16.7)$ & $1(7.7)$ \\
\hline Secondary education & $2(16.7)$ & $4(30.8)$ \\
\hline College degree & $3(25)$ & $2(15.4)$ \\
\hline University degree or higher & $5(41.7)$ & $6(46.2)$ \\
\hline Having children, $n(\%)$ & $7(58.3)$ & $10(76.9)$ \\
\hline Not employed /retired, $n$ (\%) & $10(83.3)$ & $8(61.5)$ \\
\hline \multicolumn{3}{|l|}{ Comorbidities, $n$ (\%) } \\
\hline 0 & $3(25)$ & $3(23.1)$ \\
\hline 1 & $5(41.7)$ & $2(15.4)$ \\
\hline$\geq 2$ & $4(33.3)$ & $8(61.5)$ \\
\hline Physical function (SPPB score $\geq 9$ points) & $10.3(1.2)$ & $10.8(1.0)$ \\
\hline Cognitive function (MOCA score $\geq 22$ points) & $28.3(1.9)$ & $27.5(2.4)$ \\
\hline Height, m & $1.7(0.1)$ & $1.7(0.1)$ \\
\hline Weight, kg & $68.2(12.8)$ & $68.8(14.2)$ \\
\hline Body mass index, $\mathrm{kg} / \mathrm{m}^{2}$ & $24.7(3.0)$ & $24.7(3.4)$ \\
\hline Systolic blood pressure, $\mathrm{mmHg}$ & $128.9(7.9)$ & $133.1(16.6)$ \\
\hline Diastolic blood pressure, $\mathrm{mmHg}$ & $75.7(8.9)$ & $77.9(11.9)$ \\
\hline
\end{tabular}

Values are the mean (SD) unless indicated otherwise

$n$ number; SPPB short physical performance battery, MOCA Montreal Cognitive Assessment scale

\section{Feasibility and safety}

Recruitment and retention

The flow of participants through the study is shown in Fig. 1. The intervention was advertised using 192 advertisements (145 leaflets and 47 advertisement posters), which yielded a total of 48 potential participants (45 expressing the initial interest and three recruited through friends' referrals). The recruitment rate was $25 \%$ (48/195). Two declined to participate before completing the phone-based screening. Forty-six potential participants were assessed for eligibility using the phone-based screening with 21 excluded due to not meeting the eligibility criteria $(n=18)$, declined to participate $(n=4)$ and no response $(n=1)$. Reasons for not being eligible were already physically active or taking part in another intervention $(n=11)$, or not at risk of loneliness (as assessed using the phone-screening tool) $(n=7)$. Reasons for declining to participate were pressures of work/lack of time and health reasons. A total of 31 participants $(31 / 46,67.4 \%)$ attended the further eligibility screening at Visit 1 , and 25 were eligible to proceed with baseline assessment (Visit 2). Using Wilson's 95\% confidence interval [62], at 12 weeks, 10/12 (83.3\%; 95\% CI 55.20 to 95.30 ) intervention and 10/13 (76.9\%; 95\% CI 49.74 to 91.82 ) control participants completed final assessments. The retention rate satisfied the criteria of the study, e.g. $>75 \%$ of participants at 12 weeks (end-point period), although the recruitment rate of $25 \%$ by the end of the 4 months was somewhat lower than was initially proposed at $75 \%$. There were no serious adverse events, or any adverse events observed related to study participation.

\section{Attendance}

The average attendance rate for the total of 12 sessions of the walking intervention was $58.3 \%$ for the intervention group, with attendance ranging from $33.0 \%$ to $75.0 \%$ (Additional file 6). The average attendance rate for the WL control group was $42.3 \%$, with attendance ranging from 23.1 to $69.2 \%$. The mean (SD) number of attended sessions per person was 8.6 (2.8) and 6.6 (2.6) in the intervention and wait-list control group, respectively. After completing the 12-week intervention, 7/10 participants from the intervention group and 6/10 participants from the wait-list control group continued walking. The follow-up attendance rate assessed during the 12 -week post-intervention period was $48 \%$ for the intervention and $52 \%$ for the WL control group.

\section{The assessment rate of questionnaires}

Baseline questionnaires and accelerometer data were provided by $100 \%(25 / 25)$ of participants recruited into the study. Post-intervention questionnaires and endpoint accelerometer data were provided by $100 \%(10 / 10)$ of the intervention and 100\% (10/10) WL control group participants. 


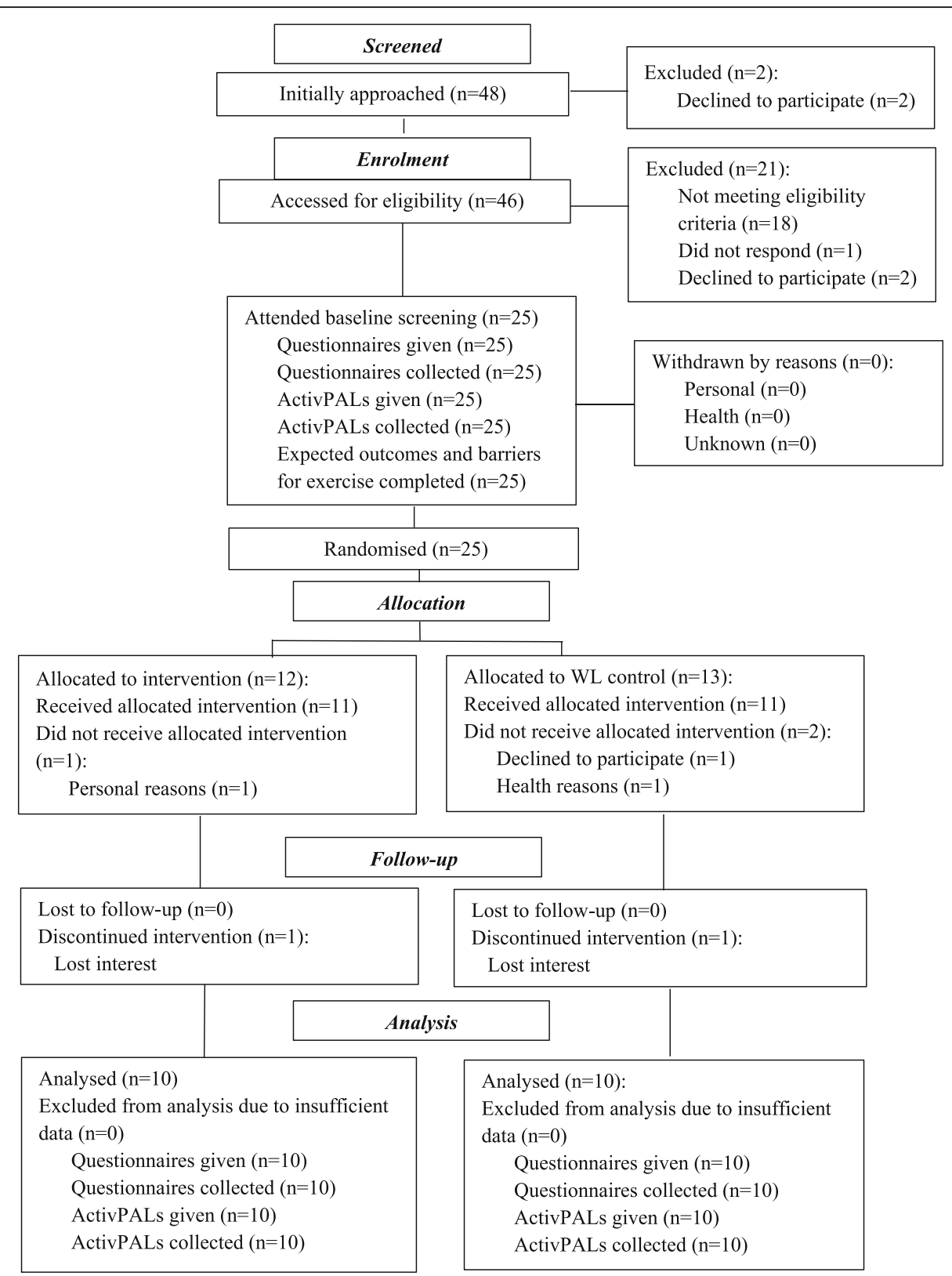

Fig. 1 CONSORT flow diagram of Physical Activity Intervention for Loneliness (PAIL) intervention.

\section{The appropriateness of the assessment tools}

The average reliability was high for all psychosocial outcomes: loneliness (Cronbach's alpha 0.857), social support (Cronbach's alpha 0.975), Lubben's social networks (Cronbach's alpha 0.721), depression (Cronbach's alpha 0.744), anxiety (Cronbach's alpha 0.693) and self-efficacy for exercise (Cronbach's alpha 0.925). The expected outcomes for the exercise sub-scale of the Expected Outcomes and Barriers for Exercise questionnaire showed high internal consistency reliability at baseline, with Cronbach's alpha equalling 0.926 (a week before) and 0.938 (a week after); at post-intervention the value was 0.976. Barriers for the exercise sub-scale of the Expected Outcomes and Barriers for Exercise questionnaire showed high internal consistency reliability at baseline, with Cronbach's alpha equalling 0.888 (a week before) and 0.924 (a week after); at the post-intervention period the value was 0.943 .

\section{Findings from the qualitative study}

The appropriateness, practicality and acceptability of the intervention by participants

A total of $5 / 12(42 \%)$ participants in the intervention group attended two focus group interviews, at the mid- 
point and end-point intervention periods. The focus group attendees were representative of the overall intervention group characteristics. The responses of participants during the focus groups were summarised in the main themes for mid-point and end-point intervention periods and presented below.

\section{Mid-point focus groups}

Participants ranged in age from $62-76$ years, $60 \%(3 / 5)$ female, $80 \%$ white, with $60 \%$ (3/5) living alone, having a university degree, having children, being retired and having one medical condition. The main themes were study design and recruitment (3 subthemes), healthy workshops (3 subthemes) and walking sessions (3 subthemes) (Additional file 4).

Mid-point focus group results showed that in terms of the appropriateness and practicality, the springsummer seasons were a better to start the intervention than winter time. Overall, participants had very positive views of the walking intervention, particularly the benefits of walking, its cost-effectiveness in terms of the economic benefits for older adults and direct positive health effects:

And because I am on a fixed income now, you know I can't just go out and earn a bit more money to do something, it does limit you a little bit in what you can do and you have got all this time, but you haven't got the money. Err, you know, and I brought up a child on my own so she took quite a lot of my salary when I was working [Kate laughs], you know I have never got a lot of money (all laugh) to do what I would really like to do. So, you have to work within that (.) (Alison, 75, female).

For others, it was a chance to meet new people and get access to local community groups:

I mean walking is good because it loosens everybody up a bit, gets people to know each other (.) (Andrew, 68, male).

The content of the healthy workshops was relevant and allowed them to share feelings and knowledge. However, the main barriers to attend walks were (1) personal, such as lack of time associated with family and community celebrations, holiday, home refurbishments, and carer responsibilities; and (2) environmental barriers, such as transportation and the weather (Additional file 3). Participants found it difficult to get to the location by public transport, or to find the nearest parking area if the meeting point was on campus:
And some of the walks, like [the place of the walk], although it wasn't that particularly early, it's getting there (.) [an issue] on public transport (Sarah, 76, female).

\section{End-point focus groups}

Participants ranged in age from 65-76 years, 20\% (1/5) female, $80 \%$ white, $60 \%$ (3/5) living alone, $40 \%(2 / 5)$ with university degree, $60 \%$ having children, retired and having one or more medical condition. The main themes were study design and recruitment (3 subthemes), healthy workshops (3 subthemes), and walking sessions (2 subthemes) (Additional file 5). Participants felt that participation in the intervention helped them to become more physically active, which was their initial aim:

You have to just try and keep motivating [yourself], just keep going I suppose, rather than just sitting at home. I don't know how (.) for me like, I am working four days a week at the moment, so I don't know how I would feel when I retire, which is going to happen next year so (.)" (Ben, male, 65).

"I enjoyed the exercise thing. It is quite, you know (.) it is just (.) She (referring to the exercise leader) sort of said, you know, made us aware of sort, of what sort of exercise is good for, what parts of your body and so forth. So, I mean it is important, isn't it to keep moving, keep active and this is what part of the programme is about, isn't it? (Ben, male, 65).

Common interests raised during the walks allowed first friendship gains that started from as early as the second or third walk and continued after the programme's end at 12 weeks. Walking was seen to promote the bonding of participants and improved their aspirations for friendship-based relationships:

I have definitely made new friends, enjoyed meeting new people and you gel with some people which is a human nature, so (.) (Sarah, female, 76).

Future recommendations included more group leaders per group and classification of walks by ability level (e.g. beginner, improver):

(.) and it was only (the Researcher). But if (the Researcher) had two other people on our walk (.). You can do a slow one slightly less (distance), a medium one slightly further and a faster one even further. I don't know how you would organise that, but that would take care of the pacing (.) The Researcher will need help. You can't do that with 
one person because you got to lead, so she actually does need somebody to lead a group (Alison, 75, female).

Another suggestion was to conduct healthy workshops during a separate session/time:

"-You suggest a separate session for loneliness workshops? (Focus group lead).

-A separate [Kate: a separate session yeah (.)] without so many leaflets (Alison, 75, female).

-Yeah, so that will be a little bit (.) it will be a good focus for each of us to learn, to share (.) (Kate, 62, female).

\section{Changes in outcome measures}

There were no significant differences between the intervention and control groups at baseline in all measures except for number $(n)$ of sit-to-stand transitions, which were 14.4 points lower in the intervention group (mean 43.3(11.3)) compared with controls (mean 57.6(15.8); 95\% CI 2.91, 25.81). Table 2 shows the between group differences for secondary outcomes. In general, a pattern of improvement was seen across all psychosocial and physical activity outcomes in the intervention group. All correlations performed for psychosocial outcomes are shown in Table 3. Correlation analysis performed for calculated change scores over time in the experimental group for all psychosocial outcomes showed no significant correlations between any other psychosocial outcomes except for a moderate negative correlation between self-efficacy for exercise and loneliness, and a moderate negative correlation between self-efficacy for exercise and the family sub-scale of Lubben's social networks. A moderate positive correlation emerged between selfefficacy for exercise and the friendship sub-scale of Lubben's social networks, such that an increase in self-efficacy for exercise was associated with a larger family and friends social network size.

Table 2 12-week group differences between intervention and control groups in anthropometric, health-related, physical activity and psychosocial outcomes from baseline

\begin{tabular}{|c|c|c|c|}
\hline \multirow[t]{2}{*}{ Variables } & \multicolumn{2}{|l|}{ Mean (SD) } & \multirow[t]{2}{*}{ Difference $(95 \%$ Cl) } \\
\hline & Intervention $(\boldsymbol{n}=12)$ & Control $(\boldsymbol{n}=13)$ & \\
\hline Height, m & $1.7(0.1)$ & $1.7(0.1)$ & $-0.0(-0.1$ to 0.1$)$ \\
\hline Weight, kg & $67.9(12.6)$ & $68.4(14.2)$ & $-0.5(-11.6$ to 10.7$)$ \\
\hline $\mathrm{BMI}, \mathrm{kg} \cdot \mathrm{m}^{-2}$ & $24.3(2.8)$ & $24.5(3.5)$ & $-0.2(-2.9$ to 2.4$)$ \\
\hline $\mathrm{SBP}, \mathrm{mmHg}$ & $123.3(8.3)$ & $129.9(13.8)$ & $-6.6(-16.1$ to 2.9$)$ \\
\hline $\mathrm{DBP}, \mathrm{mmHg}$ & $74.1(8.9)$ & $74.5(9.6)$ & $-0.4(-8.1$ to 7.3$)$ \\
\hline Loneliness & $18.1(5.2)$ & $18.6(5.2)$ & -0.5 (- 4.8 to 3.8$)$ \\
\hline Social support & $63.9(19.8)$ & $59.8(20.7)$ & 4.1 ( -12.7 to 20.9$)$ \\
\hline LSN (total) & $15.4(5.0)$ & $12.0(6.3)$ & $3.4(-1.3$ to 8.2$)$ \\
\hline LSN (family) & $6.9(4.4)$ & $5.9(3.8)$ & $1.0(-2.4$ to 4.4$)$ \\
\hline LSN (friends) & $8.5(2.5)$ & $6.1(4.9)$ & $2.4(-0.9$ to 5.7$)$ \\
\hline Depression & $6.5(3.0)$ & $5.5(3.8)$ & $1.0(-1.8$ to 3.9$)$ \\
\hline Anxiety & $6.9(3.3)$ & $7.4(3.7)$ & $-0.5(-3.4$ to 2.5$)$ \\
\hline SEE & $7.1(1.7)$ & $5.2(2.2)$ & 1.9 (0.3 to 3.6) \\
\hline SSC & $6.5(3.1)$ & $5.3(3.6)$ & $1.2(-1.7$ to 4.1$)$ \\
\hline Expected outcomes & $3.8(1.1)$ & $3.9(0.8)$ & $-0.1(-0.9$ to 0.7$)$ \\
\hline Barriers for exercise & $2.6(0.9)$ & $2.9(1.0)$ & $-0.3(-1.0$ to 0.5$)$ \\
\hline Time lying/sitting (h) & $16.8(1.9)$ & $17.1(1.8)$ & $-0.3(-1.8$ to 1.2$)$ \\
\hline Time standing (h) & $5.5(1.5)$ & $5.1(1.6)$ & $0.5(-0.9$ to 1.7$)$ \\
\hline Time stepping (h) & $1.9(0.7)$ & $1.8(0.7)$ & $0.1(-0.6$ to 0.7$)$ \\
\hline Step counts & 9067.5 (4355.7) & $8575.6(4117.5)$ & $491.9(-3013.6$ to 3997.5$)$ \\
\hline Sit to stand transitions ( $\mathrm{n}$ ) & $45.3(10.6)$ & $60.3(14.6)$ & $-15.0(-25.7$ to -4.4$)$ \\
\hline Energy Equivalent (METs/h) & $34.4(1.7)$ & $34.1(1.6)$ & $0.3(-1.1$ to 1.7$)$ \\
\hline
\end{tabular}


Table 3 Pearson product-moment correlations between change scores of psychosocial outcomes in the Intervention group $(n=12)$

\begin{tabular}{|c|c|c|c|c|c|c|c|c|c|c|}
\hline Scale & 1 & 2 & 3 & 4 & 5 & 6 & 7 & 8 & 9 & 10 \\
\hline 1. UCLA-8 & - & & & & & & & & & \\
\hline 2. MOSSSS & 0.046 & - & & & & & & & & \\
\hline 3. LSN (total) & -0.140 & 0.107 & - & & & & & & & \\
\hline 4. LSN (family) & 0.278 & 0.044 & $0.593^{*}$ & - & & & & & & \\
\hline 5. LSN (friends) & -0.470 & 0.057 & 0.313 & $-0.579^{*}$ & - & & & & & \\
\hline 6. Depression & 0.411 & -0.506 & 0.315 & 0.126 & 0.171 & - & & & & \\
\hline 7. Anxiety & 0.183 & -0.503 & -0.161 & -0.238 & 0.117 & 0.530 & - & & & \\
\hline 8. SEE & $-0.707^{*}$ & -0.148 & -0.108 & $-0.648^{*}$ & $0.655^{*}$ & -0.197 & 0.131 & - & & \\
\hline 9. SSC & -0.597 & 0.381 & 0.261 & 0.050 & 0.216 & -0.320 & $-0.741^{* *}$ & 0.425 & - & \\
\hline 10. Expected outcomes & -0.043 & 0.209 & 0.332 & 0.223 & 0.073 & -0.106 & $-0.722^{* *}$ & -0.240 & 0.563 & - \\
\hline 11. Barriers for exercise & -0.229 & -0.208 & -0.205 & -0.437 & 0.309 & 0.133 & -0.033 & 0.414 & 0.422 & -0.102 \\
\hline
\end{tabular}

UCLA-8 8-item University of California at Los Angeles loneliness scale; MOSSSS medical outcomes study social support survey, LSN Lubben's social networks, SEE self-efficacy for exercise, SSC satisfaction with level of social contacts

* Significant correlation at $p<0.05$ (two-tailed)

**Significant correlation at $p<0.01$ (two-tailed)

\section{Power calculation}

The potential sample size for a future large-scale trial was calculated for each psychosocial outcome using post hoc analyses first to estimate the observed power based on the effect sizes from the repeated measures betweenwithin ANOVAs on the 25 participants using the partial eta-squared from the interaction effect $\left(\eta^{2}\right)$. Following this, a sample size was calculated a priori for a future trial using $\alpha=0.05$ and power at $80 \%$ for each measure: loneliness $\left(n=72, \eta^{2}=0.014\right)$, social support $(n$ $\left.=48, \eta^{2}=0.030\right)$, Lubben's social network $(n=48$, $\left.\eta^{2}=0.026\right)$, depression $\left(n=378, \eta^{2}=0.008\right)$, anxiety $\left(n=68, \eta^{2}=0.032\right)$, SEE $\left(n=12, \eta^{2}=0.122\right)$, expected outcomes $\left(n=60, \eta^{2}=0.033\right)$ and barriers for exercise $\left(n=172, \eta^{2}=0.011\right)$ (Additional file 7$)$. The calculation of estimated sample size for SSC was not possible as $\eta^{2}=0.000$ (insufficient power).

\section{Discussion}

This study assessed the feasibility of the Physical Activity Intervention for Loneliness (PAIL) intervention in community-dwelling older adults at risk for loneliness. Based on the progression criteria, the retention rate was satisfactory, e.g. $>75 \%$ of participants at 12 weeks (endpoint period), as well as no adverse events during the intervention. The recruitment rate of $25 \%$ by the end of the 4 months was somewhat lower than initially proposed at $75 \%$. Therefore, only two out of three criteria of progression to the definitive RCT were satisfied, meaning that the study was not feasible to deliver in its present form. However, these findings were not surprising based on the inability to accurately estimate recruitment rates in the present study, as well as the fact that it is difficult to access socially isolated older adults who may be less interested in joining an intervention than those who are more socially engaged. Therefore, recruitment from GPs may be more advantageous than advertisement via mass media resources such as leaflets or advertisement posters in a future large-scale trial to recruit older adults at high risk of loneliness or social isolation $[20,63,64]$.

The low attendance rate $(58.3 \%$ for the intervention group, $42.3 \%$ in the WL control group) in this study is not surprising given that the PA intervention is considered to be a behaviour change strategy that is not easily initiated or consistently maintained in older adult populations [65]. Based on participant responses, providing transport to and from walking session locations may significantly improve adherence and provide easier access to various locations of walks to maintain interest of older adults.

No significant changes in outcome measures were found after 12 weeks of the PAIL intervention. As reported in the literature, the acute exercise effect is brief [66] and a longer duration intervention as well as an adequate follow-up period of the future intervention may be needed to allow participants to build upon transforming new contacts into meaningful relationships based on trust, which previous studies suggest may be up to 5 months $[67,68]$.

Given that the initial aim of the intervention was to see if loneliness could be impacted, and the observed power and estimated sample size for this seems achievable, this could be recommended as a future primary outcome. However, a feasibility study, by its very nature, may be under powered to achieve statistical significance at $\alpha=0.05$ [69]. Therefore, any interpretation based on significance levels should be treated with caution. Post hoc sample size calculations were possible; however, are not advisable for feasibility studies [70]. Therefore, 
additional feasibility testing is recommended using the minimum clinically important difference (MCID) [69], which was performed for depression and anxiety as they had a set cut-off point of 4 scores. The mean between group difference at 12 weeks was non-significant and less than the a priori determined MCID of 4 points with $95 \%$ CI crossing zero $(\mathrm{MD}=1.0,95 \% \mathrm{CI}:-1.8$ to $3.9, p=$ $0.457)$, suggesting that the results are equivocal. Similar results were obtained for anxiety $(\mathrm{MD}=-0.5,95 \% \mathrm{CI}$, -3.4 to $2.5, p=0.744)$. Given the small effect sizes for SCC, a sample size calculation was not possible, thus future feasibility testing of this measure is advised. The efficacy outcomes of the current feasibility study may be used in exploratory analyses, but further changes in the intervention design and methods are required before proceeding to a definitive trial. For example, a larger sample and more rigorous recruitment strategy, as well as easier to access walking locations may significantly improve the quality of future research. A future intervention would also be advised to (1) classify walking groups by ability level; (2) add more group leaders per group; (3) conduct healthy workshops during a separate session/time; (4) provide transport to walking locations in order to maintain high adherence and diversity of routes; and (5) conduct focus group discussions for control participants to understand their experience of the research processes, questionnaires and other elements.

\section{Strengths and limitations}

This study had a robust design and highlighted the importance of PA interventions for loneliness in older adults based on the lack of existing research [20]. Walking was chosen as it has been shown to be the most feasible and cost-effective method of physical activity for older adults [71, 72]. Other strengths of this study include objective measurement of PA, use of reliable methods of assessment of psychosocial outcomes in older adults, and the mixed methods research design that allowed for collecting feedback from participants during and at the end of the intervention.

Study limitations include selection bias associated with the recruitment of physically mobile participants as assessed during the eligibility screening. Therefore, any treatment effect of this feasibility study may be blunted by this selection bias [14, 21] and inclusion of higher functioning older adults. The identification of sedentary individuals in this study was done using the modified short form of the CHAMPS physical activity questionnaire adopted for use in an older adult population [73]. For future studies, it is advisable that instead of using this general normative definition of a sedentary individual, this exclusion criterion could be exclusive to walking. Future studies should consider using objective methods of assessment of PA (e.g. pedometers or accelerometers) in older adults in addition to the phone-based screening for a rigorous eligibility process. The optimum dose was not a feasibility outcome in the present study. However, the low attendance suggested that more frequent sessions would not be feasible. In terms of PA, the ideal dose would be a total of 150 min per week, but the present study suggests this is unlikely. Appropriate blinding of the researcher was not possible in the present study due to a lack of resources available to pay an independent person to deliver the intervention and collect all of the data. As such, it is recommended that future studies are resourced to allow for the recruitment of a trained walking leader to deliver the intervention and an independent assessor of outcomes to allow for adequate blinding and reduce detection bias. The mixed design of the intervention allowed for the enrichment of the quantitative data of the intervention by including the opinion of participants about the study. However, the low attendance of focus groups was a limitation. Out of 12 people in the intervention group, only $58.3 \%$ attended the 12-week intervention with a mean (SD) number of attended sessions per person 8.6 (2.8). The reasons for not attending focus groups were work/ lack of time, health reasons and other (e.g. transport difficulties, lack of motivation, family reasons). In addition, older adults with loneliness may have barriers for open discussions due to the "stigmatising nature of loneliness," [14, 74-76]. Therefore, a future study may consider using one-to-one interviews instead. In addition, WL control group participants may have experienced a significant nocebo effect (a worsening symptom or disappointment) [77]. Compared to control group designs with no treatment, participants with WL control group designs have a hope for the intervention delivered later; however, this may also induce frustration [78]. This may be especially true for lonely older adults with higher levels of depression or anxiety, and the likelihood of worsening their psychological well-being is high which, in turn, may influence questionnaire responses. Future research should attempt to address these issues by changing the control group design to a no treatment control, but this brings its own ethical issues surrounding not offering an intervention to individuals who have the potential to benefit from it. It should be acknowledged that even with the use of the loneliness screening measure, individuals with highest loneliness risk may be those least likely to respond to an invitation to eligibility screening due to low confidence and motivation.

\section{Conclusions}

The present study suggests that community-dwelling older adults at risk for loneliness can successfully complete a 12-week walking intervention programme, reporting enjoyment and benefits, and they were keen to share their knowledge and experiences during the 
healthy/social workshops. The efficacy outcomes of the current feasibility study may be used in exploratory analyses, but the changes suggested above to the intervention design and methods would be necessary before proceeding to a definitive trial. Further feasibility testing based on the different CIs with a MCID set a priori would be advisable.

\section{Supplementary information}

Supplementary information accompanies this paper at https://doi.org/10. 1186/s40814-020-00587-0.

Additional file 1. CONSORT extension to pilot and feasibility trials checklist

Additional file 2. The TIDieR checklist

Additional file 3. Walking programme

Additional file 4. Main themes and emerged sub-themes from the midpoint focus group interviews

Additional file 5. Main themes and emerged sub-themes from the endpoint focus group interviews

Additional file 6. Weekly average attendance rate (\%) for 12 weeks walking intervention

Additional file 7. Sample size calculations for psychosocial outcomes

\section{Abbreviations}

ANOVA: Analysis of variance; $\beta$ : The standardised regression coefficient; BMI: Body mass index; BP rest: Resting blood pressure; CHAMPS: Community Healthy Activities Model Programme for Seniors; Cl: Confidence intervals; EE: Energy expenditure; ES: Effect size; GP: General practitioner;

HADS: Hospital anxiety and depression scale; LSNS-6: 6-item Lubben's Social Network Scale; M: Mean; MCID: Minimal clinically important difference; MET: The metabolic equivalent; MOSSSS: Medical Outcomes Study Social Support Survey; MOCA: Montreal Cognitive Assessment; MVPA: Moderate-tovigorous physical activity; N: Number; NHS: National Health Services; PA: Physical activity; PAIL: Physical activity intervention for loneliness; R: Correlation coefficient; RCT: Randomised controlled trial; RPE: Ratings of perceived exertion scale; SD: Standard deviation; SEE: Self-efficacy for exercise scale; SSC: Satisfaction with level of social contacts; SPPB: Short physical performance battery; STEM Ethical Review Committee: Science, Technology, Engineering and Mathematics Ethical Review Committee; TIDieR: Template for intervention description and replication checklist; UCLA-8: 8-item The University of California, Los Angeles Loneliness Scale; UK: United Kingdom; WL: Wait-listed control group

\section{Acknowledgements}

The lead author of this paper is funded by a Russian government-sponsored scholarship programme "Global Education", Moscow School of Management "Skolkovo" (Grant number 35). We would like to acknowledge Farhan Noordali (Doctor of Philosophy, University of Birmingham) for acting as a moderator of the focus group interviews and Meike Rosemeyer (PhD student, University of Birmingham) for helping to assist with focus group interviews.

\section{Disclosure statement}

The authors of this review declare that they have no known conflicts of interest.

\section{Authors' contributions}

AW, JT and CG advised regarding development of trial design and study protocol, assisted obtaining ethics approval and amendments, helped in facilitating patient recruitment, register study protocol, structure the research stages and oversee all study procedures. JT also helped to design and analyse focus group interviews. FN helped to conduct and analyse focus group interviews. The doctoral research student (AS) obtained funding and was involved in the design of the study protocol, participant recruitment, health assessments and implementation of the intervention. The author(s) read and approved the final manuscript.

\section{Authors' information}

AW is Professor in Behavioural Medicine, JT is a Professor of Public Health Nutrition and Exercise, CAG is a Reader in Musculoskeletal Ageing and Health, all at the School of Sport, Exercise and Rehabilitation Sciences, University of Birmingham, UK.

\section{Funding}

The lead author of this paper is funded by a Russian government-sponsored scholarship programme "Global Education", Moscow School of Management "Skolkovo" (Grant number 35). Additional funding was supported by the School of Sport, Exercise and Rehabilitation Sciences at the University of Birmingham.

\section{Availability of data and materials}

Not applicable.

\section{Consent for publication}

Not applicable.

\section{Competing interests}

The authors of this article declare that they have no competing interests.

\section{Author details}

${ }^{1}$ School of Sport, Exercise and Rehabilitation Sciences, University of Birmingham, Birmingham, UK. ${ }^{2}$ MRC - Arthritis Research UK Centre for Musculoskeletal Ageing Research, University of Birmingham, Birmingham, UK. ${ }^{3}$ Faculty of Health Sciences and Sport, University of Stirling, Stirling, UK. ${ }^{4} \mathrm{NIHR}$ Birmingham Biomedical Research Centre, University Hospitals Birmingham NHS Foundation Trust and University of Birmingham, Birmingham, UK.

Received: 14 March 2019 Accepted: 19 March 2020

Published online: 23 May 2020

\section{References}

1. Cacioppo JT, Cacioppo S. Social relationships and health: the toxic effects of perceived social isolation. Soc Pers Psychol Compass. 2014;8:58-72. https:// doi.org/10.1111/spc3.12087.

2. Poscia A, Stojanovic J, La Milia Dl, et al. Interventions targeting loneliness and social isolation among the older people: an update systematic review. Exp Gerontol. 2018;102:133-44

3. Peplau LA, Cutrona CE. The revised UCLA Loneliness Scale: concurrent and discriminant validity evidence. J Pers Soc Psychol. 1980;39:472-80.

4. Holt-Lunstad J, Smith TB, Layton JB. Social relationships and mortality risk: a meta-analytic review. PLoS Med. 2010;7:e1000316.

5. Department of Health. Start active, stay active: report on physical activity in the UK 2016 [https://www.gov.uk/government/publications/start-active-stayactive-a-report-on-physical-activity-from-the-four-home-countries-chiefmedical-officers].

6. Physical Activity Guidelines Advisory Committee. 2018 physical activity guidelines advisory committee scientific report Washington, DC: U.S. Departament of Health and Human Services: 2018.

7. Mindell J, Biddulph JP, Hirani V, et al. Cohort profile: the health survey for England. Int J Epidemiol. 2012;41:1585-93.

8. Haskell WL, Lee I-M, Pate RR, et al. Physical activity and public health: updated recommendation for adults from the American College of Sports Medicine and the American Heart Association. Circulation. 2007;116:1081.

9. Penedo FJ, Dahn JR. Exercise and well-being: a review of mental and physical health benefits associated with physical activity. Curr Opin Psychiatry. 2005;18:189-93.

10. Ferraro KF, Farmer MM. Social compensation in adulthood and later life. In: Dixon RA, Backman L, editors. Compensating for psychological deficits and declines: managing losses and promoting gain. United States of America: Lawrence Erlbaum Associates; 1995. p. 127-45.

11. Biddle SJ, Asare M. Physical activity and mental health in children and adolescents: a review of reviews. British J Sports Med. 2011;45:886-96. 
12. Lubans D, Richards J, Hillman C, et al. Physical activity for cognitive and mental health in youth: a systematic review of mechanisms. Pediatrics. 2016: e20161642.

13. Ferraro KF, Farmer MM. Social compensation in adulthood and later life. Compensating Psychol Deficits Declines. 1995:127-45.

14. Stevens $N$ Combating loneliness: a friendship enrichment programme for older women. Ageing Soc. 2001;21:183-202. doi: https://doi.org/https://doi. org/10.1017/S0144686X01008108.

15. Fredrickson BL. The broaden-and-build theory of positive emotions. Philos Trans R Soc Lond B Biol Sci. 2004:1367-78. https://doi.org/10.1098/rstb.2004.1512.

16. Newall NE, Chipperfield JG, Bailis DS, et al Consequences of loneliness on physical activity and mortality in older adults and the power of positive emotions. Health Psychol. 2013;32:921. doi: http://dx.doi.org/https://doi.org/ 10.1037/a0029413

17. Cohen S, Wills TA. Stress, social support, and the buffering hypothesis. Psychol Bull. 1985;98:310

18. Pels F, Kleinert J. Loneliness and physical activity: a systematic review. Int Rev Sport Exerc Psychol. 2016;9:1-30. doi: https://doi.org/https://doi.org/10. 1080/1750984X.2016.1177849

19. Henry KB, Arrow H, Carini B. A tripartite model of group identification theory and measurement. Small Group Res. 1999;30:558-81.

20. Shvedko A, Whittaker AC, Thompson JL, et al Physical activity intervention for treatment of social isolation, loneliness or low social support in older adults: a systematic review and meta-analysis of randomised controlled trials. Psychol Sport Exerc. 2018;34:128-137. doi: https://doi.org/https://doi. org/10.1016/j.psychsport.2017.10.003.

21. Masi CM, Chen H-Y, Hawkley LC, et al. A meta-analysis of interventions to reduce loneliness. Pers Soc Psychol Rev. 2010:219-66.

22. Smith GL, Banting L, Eime R, et al. The association between social support and physical activity in older adults: a systematic review. Int J Behav Nutr Phys Activ. 2017;14:56. https://doi.org/10.1186/s12966-017-0509-8.

23. Fry PS. Predictors of health-related quality of life perspectives, self-esteem, and life satisfactions of older adults following spousal loss an 18-month follow-up study of widows and widowers. Gerontologist. 2001;41:787-98.

24. Bandura A. Perceived self-efficacy in cognitive development and functioning. Educ Psychol. 1993;28:117-48.

25. Fry PS, Debats DL. Self-efficacy beliefs as predictors of loneliness and psychological distress in older adults. Int J Aging Hum Dev. 2002;55:233-69.

26. Taliaferro LA, Rienzo BA, Miller DM, et al. Potential mediating pathways through which sports participation relates to reduced risk of suicidal ideation. Res Q Exerc Sport. 2010;81:328-39.

27. Eldridge SM, Lancaster GA, Campbell MJ, et al. Defining feasibility and pilot studies in preparation for randomised controlled trials: development of a conceptual framework. PloS One. 2016;11:e0150205.

28. Johnson RB, Onwuegbuzie AJ. Mixed methods research: a research paradigm whose time has come. Educ Res. 2004;33:14-26.

29. Eldridge SM, Chan CL, Campbell MJ, et al. CONSORT 2010 statement: extension to randomised pilot and feasibility trials. Pilot Feasibility Stud. 2016;2:64.

30. Shvedko AV, Thompson JL, Greig CA, et al. Physical activity intervention for loneliness (PAIL) in community-dwelling older adults: protocol for a feasibility study. Pilot Feasibility Stud. 2018:4:187. https://doi.org/10.1186/ s40814-018-0379-0.

31. Hoffmann TC, Glasziou PP, Boutron I, et al. Better reporting of interventions: template for intervention description and replication (TIDieR) checklist and guide. Bmj. 2014;348:g1687

32. Miles MB, Huberman AM. Qualitative data analysis: a sourcebook. Beverly Hills: Sage Publications; 1994

33. Arain M, Campbell MJ, Cooper CL, et al. What is a pilot or feasibility study? A review of current practice and editorial policy. BMC Med Res Methodol. 2010;10:67.

34. Stevens M, Hillsdon M, Thorogood M, et al. Cost-effectiveness of a primary care based physical activity intervention in 45-74 year old men and women: a randomised controlled trial. British J Sports Med. 1998:32:236-41.

35. Hughes ME, Waite LJ, Hawkley LC, et al. A short scale for measuring loneliness in large surveys results from two population-based studies. Res Aging. 2004;26:655-72

36. Guralnik JM, Simonsick EM, Ferrucci L, et al. A short physical performance battery assessing lower extremity function: association with self-reported disability and prediction of mortality and nursing home admission. $J$ Gerontol. 1994;49:M85-94.
37. Pahor M, Guralnik JM, Ambrosius WT, et al. Effect of structured physical activity on prevention of major mobility disability in older adults: the LIFE study randomized clinical trial. JAMA. 2014;311:2387-96. https://doi.org/10. 1001/jama.2014.5616.

38. Nasreddine ZS, Phillips NA, Bédirian V, et al. The Montreal Cognitive Assessment, MoCA: a brief screening tool for mild cognitive impairment. JAGS. 2005;53:695-9. https://doi.org/10.1111/j.1532-5415.2005.53221.x.

39. Freitas $S$, Simões MR, Alves $L$, et al. Montreal cognitive assessment: validation study for mild cognitive impairment and Alzheimer disease. Alzheimer Dis Assoc Disord. 2013;27:37-43.

40. Lemon BW, Bengtson VL, Peterson JA. An exploration of the activity theory of aging: activity types and life satisfaction among in-movers to a retirement community. J Gerontol. 1972;27:511-523. doi: https://doi.org/ https://doi.org/10.1093/geronj/27.4.511.

41. Move it or lose it. 2019 [https://www.moveitorloseit.co.uk/]. Accessed 2019.

42. The Birmingham 1000 Elders group. 2017 [https://www.birmingham.ac.uk/ research/activity/mds/centres/healthy-ageing/elders.aspx].

43. Birmingham Voluntary Service Council. The consotrium of ageing better 2016 [https://www.bvsc.org/]

44. American College of Sports Medicine. ACSM's guidelines for exercise testing and prescription: Lippincott Williams \& Wilkins; 2013.

45. Fox SM, Naughton JP, Haskell WL. Physical activity and the prevention of coronary heart disease. Ann Clin Res. 1971;3:404-32.

46. Persinger R, Foster $\mathrm{C}$, Gibson M, et al. Consistency of the talk test for exercise prescription. Med Sci Sports Exerc. 2004;36:1632-6. https://doi.org/ 10.1249/01.MSS.0000074670.03001.98

47. Borg E, Kaijser L. A comparison between three rating scales for perceived exertion and two different work tests. Scand J Med Sci Sports. 2006;16:57-69.

48. Chastin S, Granat M. Methods for objective measure, quantification and analysis of sedentary behaviour and inactivity. Gait Posture. 2010:31:82-86. doi: https://doi.org/https://doi.org/10.1016/j.gaitpost.2009.09.002.

49. Hays RD, DiMatteo MR. A short-form measure of loneliness. J Pers Assess. 1987;51:69-81.

50. Sherbourne CD, Stewart AL. The MOS social support survey. Soc Sci Med. 1991;32:705-14.

51. Lubben J, Blozik E, Gillmann G, et al. Performance of an abbreviated version of the Lubben Social Network Scale among three European communitydwelling older adult populations. Gerontologist. 2006;46:503-13.

52. Zigmond AS, Snaith RP. The hospital anxiety and depression scale. Acta Psychiatrica Scandinavica. 1983;67:361-70.

53. Resnick B, Jenkins LS. Testing the reliability and validity of the self-efficacy for exercise scale. Nurs Res. 2000:49:154-9.

54. Fokkema T, Knipscheer K. Escape loneliness by going digital: a quantitative and qualitative evaluation of a Dutch experiment in using ECT to overcome loneliness among older adults. Ageing \& Mental Health. 2007;11:496-504. https://doi.org/10.1080/13607860701366129.

55. Steinhardt MA, Dishman RK. Reliability and validity of expected outcomes and barriers for habitual physical activity. Journal of Occupational and Environmental Medicine. 1989:31:536-46.

56. MacDougall C, Fudge E. Planning and recruiting the sample for focus groups and in-depth interviews. Qualitative health research. 2001;11:117-26.

57. Creswell JW. Qualitative inquiry and research design: choosing among five approaches: Sage publications; 2012.

58. Erdfelder E, Faul F, Buchner A. GPOWER: a general power analysis program. Behavior research methods, instruments, \& computers. 1996;28:1-11.

59. Gupta SK. Intention-to-treat concept: a review. Perspectives in Clinical Research. 2011;2:109-12. https://doi.org/10.4103/2229-3485.83221.

60. Fossey E, Harvey C, McDermott F, et al. Understanding and evaluating qualitative research. Australian and New Zealand journal of psychiatry. 2002; 36:717-32.

61. Tesch R. Qualitative research: analysis types and software: Routledge; 2013.

62. Wilson EB. Probable inference, the law of succession, and statistical inference. Journal of the American Statistical Association. 1927;22:209-12.

63. Age Concern UK. Loneliness and isolation evidence review 2016 [www. ageuk.org.uk/documents/en-gb/for-professionals/].

64. Jopling K Promising approaches to reducing loneliness and isolafion in later life. 2015 [http://www.campaigntoendloneliness.org/wp-content/uploads/ Promising-approaches-to-reducing-loneliness-and-isolation-in-later-life.pdf]

65. Horne E, Lancaster GA, Matson R, et al. Pilot trials in physical activity journals: a review of reporting and editorial policy. Pilot and feasibility studies. 2018;4:125. 
66. Chodzko-Zajko WJ. Exercise and physical activity for older adults. 2014. https://doi.org/10.1249/MSS.0b013e3181a0c95c.

67. Findlay RA. Interventions to reduce social isolation amongst older people: where is the evidence? Ageing and Society. 2003;23:647-58.

68. McAuley E, Blissmer B, Katula J, et al Exercise environment, self-efficacy, and affective responses to acute exercise in older adults. Psychology and Health. 2000;15:341-55. doi: http://dx.doi.org/https://doi.org/10.1080/ 08870440008401997.

69. Lee EC, Whitehead AL, Jacques RM, et al. The statistical interpretation of pilot trials: should significance thresholds be reconsidered? BMC medical research methodology. 2014;14:41.

70. Walters SJ. Consultants'forum: should post hoc sample size calculations be done? Pharmaceutical Statistics: The Journal of Applied Statistics in the Pharmaceutical Industry. 2009;8:163-169.

71. Townsend N, Bhatnagar P, Wickramasinghe K, et al. Physical activity statistics 2012. London: British Heart Foundation; 2012.

72. Mutrie N, Doolin O, Fitzsimons CF, et al. Increasing older adults' walking through primary care: results of a pilot randomized controlled trial. Family practice. 2012:633-42.

73. Stewart AL, Mills KM, King AC, et al. CHAMPS physical activity questionnaire for older adults: outcomes for interventions. Med Sci Sports Exerc. 2001;33: 1126-41.

74. Griffin J. The lonely society?: Mental Health Foundation; 2010

75. Peplau LA, Miceli M, Morasch B. Loneliness and self-evaluation. Loneliness: a sourcebook of current theory, research and therapy. New York: WileyInterscience; 1982. p. 135-151.

76. Wenger GC, Burholt V. Changes in levels of social isolation and loneliness among older people in a rural area: a Twenty-Year Longitudinal Study. Canadian Journal on Aging/la revue canadienne du vieillissement. 2004;23: 115-27.

77. Furukawa $\mathrm{T}$, Noma $\mathrm{H}$, Caldwell $\mathrm{D}$, et al. Waiting list may be a nocebo condition in psychotherapy trials: a contribution from network metaanalysis. Acta Psychiatrica Scandinavica. 2014;130:181-92.

78. Gold SM, Enck P, Hasselmann H, et al. Control conditions for randomised trials of behavioural interventions in psychiatry: a decision framework. The lancet Psychiatry. 2017;4:725-32.

\section{Publisher's Note}

Springer Nature remains neutral with regard to jurisdictional claims in published maps and institutional affiliations.

Ready to submit your research? Choose BMC and benefit from:

- fast, convenient online submission

- thorough peer review by experienced researchers in your field

- rapid publication on acceptance

- support for research data, including large and complex data types

- gold Open Access which fosters wider collaboration and increased citations

- maximum visibility for your research: over $100 \mathrm{M}$ website views per year

At BMC, research is always in progress.

Learn more biomedcentral.com/submissions 